\title{
Preconception Health Trajectories and Birth Weight in a National Prospective Cohort
}

\author{
Kelly L. Strutz, MPH, Liana J. Richardson, PhD, and Jon M. Hussey, PhD \\ Carolina Population Center (Ms. Strutz and Drs. Richardson and Hussey), Department of \\ Maternal and Child Health, Gillings School of Global Public Health (Ms. Strutz and Dr. Hussey), \\ and Department of Sociology (Dr. Richardson), The University of North Carolina at Chapel Hill
}

\begin{abstract}
Purpose-This study was designed to assess the relationship between birth weight and prospectively measured trajectories of preconception health across adolescence and young adulthood in a diverse national cohort of young adult women.
\end{abstract}

Methods-Data came from Waves I (1994-95), III (2001-02), and IV (2007-08) of the National Longitudinal Study of Adolescent Health. Eligibility was restricted to all the singleton live births $(\mathrm{N}=3436)$ to female participants occurring between the Wave III (ages 18-26) and Wave IV (ages 24-32) interviews. Preconception cigarette smoking, overweight/obesity, adequate physical activity, heavy alcohol consumption, and fair/poor self-rated health were measured in adolescence (Wave I) and early adulthood (Wave III) and combined into 4-category variables to capture the timing and sequencing of exposure. The outcome measure, birth weight, was classified as low (<2500 grams), normal (2500-4000 grams), and macrosomic (>4000 grams).

Results-Multinomial logistic regression results indicated that adult-onset overweight significantly increased the odds of having a macrosomic birth (odds ratio $=1.56 ; 95 \%$ confidence interval, 1.02-2.38).

Conclusions-This study provides new evidence about the influence of maternal body mass index trajectories on offspring birth weight. Adult-onset overweight/obesity during the transition to adulthood was common in the sample and increased the odds of subsequently delivering a macrosomic infant by $56 \%$. This finding suggests that healthy weight promotion prior to this transition would confer intergenerational benefits, and supports recommendations for preconception care to address overweight/obesity.

\section{Keywords}

preconception health; low birth weight; macrosomia; longitudinal analyses; overweight; obesity; adolescent; young adult

\footnotetext{
(C) 2012 Society for Adolescent Medicine. Published by Elsevier Inc. All rights reserved.

Correspondence: Kelly L. Strutz, MPH, Carolina Population Center, University of North Carolina at Chapel Hill, CB\# 8120, University Square, 123 W. Franklin St., Chapel Hill, NC 27516-2524. Telephone: 919-448-8316. Fax: 919-966-6638. strutz@email.unc.edu.
}

\section{IMPLICATIONS AND CONTRIBUTION}

This study examines the effects of prepregnancy health status, across adolescence and young adulthood, on infant birth weight. It provides new evidence that adult-onset overweight/obesity increases the odds of delivering a heavy infant, and suggests that healthy weight maintenance from adolescence into adulthood benefits the next generation.

Publisher's Disclaimer: This is a PDF file of an unedited manuscript that has been accepted for publication. As a service to our customers we are providing this early version of the manuscript. The manuscript will undergo copyediting, typesetting, and review of the resulting proof before it is published in its final citable form. Please note that during the production process errors may be discovered which could affect the content, and all legal disclaimers that apply to the journal pertain. 
Both restricted and excessive birth weights increase risks for infant mortality [1,2], as well as a variety of short- and long-term developmental and health problems, including cardiovascular and metabolic disorders $[3,4]$. The prevailing approach to research on these outcomes is to examine risk factors during the prenatal period. However, this period may be too narrow and come too late to identify and address all modifiable risk factors for adverse birth outcomes [5-7]. As a result, major government health agencies and prominent medical organizations now view the promotion of "preconception" health, or health before pregnancy, as a promising strategy to reduce infant mortality and other adverse birth outcomes $[8,9]$. Consistent with a life course perspective on maternal and child health $[10,11]$, this recommendation acknowledges that birth outcomes are affected not only by maternal exposures during the prenatal period but also by exposures across the life course. The reproductive period spanning adolescence and the transition to adulthood may be particularly critical given its documented salience for future health [12]. As a result, management of high-risk behaviors that often emerge well before the onset of childbearing, such as tobacco and alcohol use and unhealthy weight maintenance, has been recommended as an especially important preconception care strategy in Healthy People 2020 objectives [13] and clinical guidelines [14].

While preconception care can play an important role in improving or maintaining women's health, there is sparse evidence linking it or indicators of preconception health status to infant health outcomes. Studies of prepregnancy obesity-the most common preconception health studies--have tied it to macrosomia and other infant health complications [15]. Other research has documented links between retrospectively-reported prepregnancy alcohol consumption or physical activity and fetal growth $[16,17]$. Studies that view preconception health as multifactorial have been confined to small samples of potentially limited generalizability, and hampered by retrospective reports of exposures [6] or prospective measures reported in a narrow window of time prior to the pregnancy [18]. In contrast to these approaches, the life course perspective compels us to examine the occurrence and timing of exposures across the entire life span [10]. Although researchers have begun to examine the impact of maternal exposures during childhood or adolescence on subsequent birth outcomes in national cohorts [19,20] or smaller non-representative samples [21], no longitudinal studies have focused exclusively on the modifiable risk factors emphasized in preconception care recommendations. Moreover, no longitudinal studies have focused on measures of overall prepregnancy health from adolescence through young adulthood.

To fill these gaps, we assessed the effects of prospectively measured preconception health trajectories (i.e., trajectories of cigarette smoking, overweight/obesity, adequate physical activity, heavy alcohol consumption, and fair or poor self-rated health) on low birth weight (LBW, < 2500 grams) and macrosomia (> 4000 grams). We used the National Longitudinal Study of Adolescent Health (Add Health) -- a unique data source that allowed us to examine preconception health longitudinally across adolescence and young adulthood in a national cohort of United States (US) women. The aims of this study were to contribute novel information regarding the strength of associations between preconception factors and offspring birth weight, to assess whether the associations depend on the timing and sequencing of repeated exposures to preconception factors, and to evaluate whether these relationships are mediated by prenatal factors. Consistent with a life course perspective, we hypothesized that the timing and sequencing of preconception exposures would be consequential for birth weight, and that preconception health would impact birth weight both directly and indirectly through prenatal exposures. 


\section{METHODS}

We used restricted-use data from Waves I, III, and IV of Add Health, a prospective cohort study of a nationally representative probability sample of US adolescents in grades 7 through 12 (ages 11-19) in the 1994-95 school year. From April to December of 1995, 20,745 Wave I in-home interviews were completed (79\% response rate). At this time, a parent also completed an interviewer-assisted questionnaire. We did not use data from Wave II because it was conducted just one year after Wave I. In 2001-02, Wave III in-home interviews were completed with 15,170 respondents aged 18 to 26 (77\% response rate). At Wave IV (2007-08) in-home interviews were completed with 15,701 respondents aged 2432 years ( $80 \%$ response rate). A complete description of the Add Health study design and sample is available elsewhere [22]. All Add Health procedures and the present study were approved by the Public Health Institutional Review Board (IRB) at the University of North Carolina, Chapel Hill.

The analytic sample for the present study consisted of all singleton live births occurring between Waves III and IV to female respondents who had valid sampling weights and completed interviews at Waves I, III, and IV. We excluded live births if they occurred prior to or within 42 weeks of the Wave III interview $(n=3337)$ to ensure that exposures measured at Wave III were temporally prior to the prenatal period and the births included in the analysis. We also excluded live births resulting from multiple gestations $(n=159)$ or missing information on birth weight ( $\mathrm{n}=37)$. A total of 3436 births to 2615 respondents were retained in our sample. The mean interval between Wave III interview and birth for the sample was 1364 days (approximately 4 years).

\section{Measures}

We obtained infant birth weight from maternal responses to the question "How much did \{baby's name\} weigh at birth?" at Wave IV, and converted them from pounds and ounces to grams for consistency with clinical measurement. Birth weight was categorized into LBW (< 2500 grams), normal ( $2500-4000$ grams), or macrosomia (> 4000 grams) to examine higher-risk outcomes at both ends of the birth weight distribution. Respondents who were unable to recall their infant's exact weight $(n=46)$ were asked if the infant weighed less than 5 pounds, 8 ounces at birth, which allowed us to classify 9 births as LBW that would have otherwise been excluded from the study.

Preconception exposures were cigarette smoking, overweight or obesity, adequate physical activity, heavy alcohol consumption, and fair or poor self-rated health measured prospectively at Waves I (adolescence) and III (young adulthood). These exposures were chosen to reflect Healthy People 2020 objectives [13] and clinical guidelines [14] for preconception care. We defined cigarette smoking as any smoking in the past 30 days. Using respondent height and weight (self-reported at Wave I and interviewer measured at Wave III), we defined adolescent overweight/obesity as reaching or exceeding the $85^{\text {th }}$ percentile for the age- and sex-specific Centers for Disease Control and Prevention (CDC) growth charts of body mass index (BMI, calculated as weight in kilograms divided by height in meters squared) [23] and adult overweight/obesity as BMI $\geq 25 \mathrm{~kg} / \mathrm{m}^{2}$ [24]. To approximate the US guidelines for energy expenditure, we defined adequate physical activity as participating in 5 or more bouts of moderate to vigorous physical activity in the past week $[25,26]$. We defined heavy alcohol consumption as consuming $>3$ drinks/day or $>7$ drinks/ week in the past year [27]. We defined fair or poor self-rated health as reporting fair or poor health on a 5-point scale ranging from poor to excellent. These dichotomous measures were combined across the two waves to create a 4-category variable (occurring at neither time point, in adolescence only, in young adulthood only, or at both time points) that captured the timing and sequencing of each exposure trajectory. 
Prenatal covariates evaluated as potential mediators were measures of maternal cigarette smoking during pregnancy (yes/no), alcohol consumption during pregnancy (yes/no), and timing of entry into prenatal care (first trimester, second trimester, third trimester, or never) as reported by the respondent at Wave IV.

We included the following measures as potential confounders because of their known or suspected relationships with preconception or prenatal health status and infant birth weight: respondent's age and parity (nulliparous/parous) at the time of the birth; self-identified race/ ethnicity (non-Hispanic White, non-Hispanic Black, Latina, Asian/Pacific Islander, or other); nativity (foreign-born to foreign-born parent, native-born to foreign-born parent, or native-born to native-born parent); and two indicators of respondent's childhood socioeconomic status (SES): her mother's educational attainment (less than high school, general educational development certificate [GED], high school diploma, some college or trade school, or completed college or more), and any household receipt of public assistance prior to age 18 (yes/no).

\section{Statistical analysis}

We examined variable distributions across the three categories of birth weight using univariate and bivariate statistics. We used multinomial logistic regression to estimate the odds of LBW and macrosomia for each of the preconception health trajectories with normal birth weight as the referent category. We used multiple multinomial logistic regression to obtain adjusted odds ratios for LBW and macrosomia controlling for potential confounders, and to evaluate whether inclusion of prenatal factors attenuated associations between preconception health and birth weight, consistent with mediation.

We accounted for Add Health's complex survey design in all analyses. Prior to this accounting, sampling weights for respondents with more than one eligible birth in the analytic sample were divided equally among the births to account for autocorrelation; this method results in a pseudoweight similar to the sandwich estimators used in generalized estimating equations and other population-averaged models [28]. Analyses were conducted using Stata version 11 (StataCorp, College Station, TX).

\section{RESULTS}

\section{Sample Characteristics}

Of the 3436 total births in our sample, $8.3 \%$ were LBW and 9.5\% were macrosomic (Table 1). While the women in this study were diverse in terms of race/ethnicity, nativity, and childhood SES, the upper panel of Table 1 also reveals that Non-Hispanic Black women contributed a disproportionate share of LBW deliveries while Non-Hispanic White mothers were overrepresented among the macrosomic births. Foreign-born women were less likely than native-born women to deliver both low and high birth weight infants, and macrosomic births were less common among women from low childhood SES origins than among women from higher childhood SES origins.

Preconception health risks were common, with $47 \%$ of women reporting a history of smoking and $44 \%$ reporting heavy drinking. Over half of all women (53\%) had a history of overweight or obesity and $28 \%$ reported low physical activity in both adolescence and early adulthood. In addition, $13 \%$ of women reported fair or poor health at either time point. In terms of prenatal risk factors, $21 \%$ self-reported smoking during pregnancy and $6 \%$ selfreported any prenatal alcohol use. The majority of women entered prenatal care in their first trimester and less than $2 \%$ received no prenatal care. 


\section{Bivariate and Multivariate Associations}

Of the five preconception factors examined, only one-overweight/obesity - was significantly associated with birth weight in all models (Table 2). The odds of a LBW delivery (Table 2, column 1) more than tripled among women with adolescence-only overweight/obesity (odds ratio [OR] $=3.89 ; 95 \%$ confidence interval [CI], 1.26-12.04]. This association strengthened and remained significant after adjusting for potential confounders and hypothesized prenatal mediators $(\mathrm{OR}=4.59$; $\mathrm{CI}, 1.26-16.70$; Table 2, column 3). Preconception overweight/obesity also was associated with the odds of delivering heavy infants. Specifically, adult onset overweight/obesity significantly increased the odds of having a macrosomic birth - an association that persisted after adjusting for potential confounders $(\mathrm{OR}=1.56$; $\mathrm{CI}, 1.02-2.38$; Table 2; column 5). This association weakened slightly and was no longer statistically significant after inclusion of the prenatal mediators $(\mathrm{OR}=1.52$; CI, 0.99-2.34; Table 2, column 6).

We repeated the analyses with alternative definitions of adolescent and/or adult overweight/ obesity to determine if the results were sensitive to our definitions. The sensitivity analyses (Table 3) indicated that the association between weight gain in the transition to adulthood and macrosomia was robust. The odds of macrosomic birth for adult-onset obesity was approximately the same whether the adolescent BMI cut-point was the $85^{\text {th }}$ or $95^{\text {th }}$ percentile of age- and sex-specific growth charts, and whether the adult BMI cut-point was $\geq$ $25 \mathrm{~kg} / \mathrm{m}^{2}$ or $\geq 30 \mathrm{~kg} / \mathrm{m}^{2}$. In contrast, the association between weight loss during the transition to adulthood and LBW was sensitive to the BMI thresholds used to define adolescent and adult weight status.

\section{DISCUSSION}

There is great interest in how preconception exposures impact birth outcomes, but little evidence. By examining the relationship between preconception health and birth weight in a large and diverse national prospective cohort, this study has extended our knowledge about life course influences on perinatal health in several important ways. First, because we used data from a prospective national cohort study, our study removes the biases associated with and is more generalizable than the more common approaches to research on birth outcomes -namely the use of samples drawn from prenatal clinic populations or medical records and the reliance on retrospective recall of prepregnancy events. Second, consistent with a life course perspective, we expanded the preconceptional exposure period beyond the typical research focus on the weeks or months immediately prior to pregnancy to capture health in adolescence and early adulthood, with an average lapse of 4 years between the preconception measures and the births. For many women in our study, adolescence predated not only the births included in the analysis but also their overall childbearing history and plans. Third, to understand whether trajectories of preconception health are consequential, we studied the impact of stability and change in health risks during the critical transition to adulthood. Finally, because births at both ends of the distribution are clinically significant due to their short- and long-term health consequences, we modeled preconception influences on LBW and macrosomia while most birth weight research tends to focus on just one of these outcomes.

The results of this study point to preconception BMI as a particularly important contributor to infant birth weight. Our finding that preconception overweight/obesity increases the odds of macrosomia is consistent with prior results from studies conducted in Central Pennsylvania [18], Washington State [29], and Norway [30]. In addition to replicating these findings in a national cohort of US young adult women, our study is the first that we know of to provide evidence about how longitudinal BMI trajectories influence future birth outcomes. Contrary to expectation, persistent overweight/obesity in adolescence and early 
adulthood, which characterized $16 \%$ of the women in the sample, did not significantly increase the odds of macrosomia. Instead, the strongest association between preconception overweight/obesity and macrosomia risk was found among women who became overweight/ obese between adolescence and early adulthood. This association was robust to alternative specifications of adolescent and adult overweight/obesity, and was attenuated only slightly by the addition of prenatal mediators to the model. This finding is extremely important, considering the high incidence of emergent overweight/obesity among women during the transition to adulthood ( $28 \%$ in our sample). Importantly, it builds on previous evidence that this period of the life course is critical for long-term health trajectories [12,31] by suggesting that, in the context of female childbearing, this period also has intergenerational consequences.

We also found an association between overweight in adolescence only and LBW. Although this finding held after controlling for potential confounders and prenatal mediators, it was sensitive to the definitions of weight status used. Therefore, this association was likely an artifact. In addition, only $1 \%$ of our sample followed this trajectory. Consequently, the ORs were imprecise with wide confidence intervals and the public health impacts are negligible.

We found no significant relationship between preconception physical activity and birth weight. Few other studies of this relationship exist and their findings have been mixed, probably due to vast differences in sample composition, analytic approach, and measurement of physical activity $[16,18,32,33]$. To our knowledge, only one other prospective study of birth outcomes with a measure of preconception physical activity comparable to ours has been conducted, also finding no association [18].

The absence of an association between preconception substance use and birth weight in this large and diverse national cohort is noteworthy. The few studies of this relationship have typically reported significant crude associations that either persist $[17,34]$ or disappear $[35,36]$ after adjusting for prenatal factors and potential confounders. However, recall bias associated with retrospective reports of preconception health is one possible contributor to these mixed findings. Our finding of no crude or adjusted associations between preconception cigarette or alcohol use and birth weight is consistent with the only other study to have measured these behaviors prospectively [18], and with other evidence that preconception smoking cessation can mitigate the adverse impact of cigarette use on birth weight [37].

\section{Limitations}

Several limitations of our study must be noted. First, preconception exposures were measured only at two time points, and thus may not reflect the entire exposure history of each participant. This limitation also makes it difficult to discern whether the preconception period included in our analysis represents a critical period, and to identify pathway or cumulative effects. Second, adolescent BMI was calculated from self-reported height and weight, but these measures have been demonstrated to be reliable in adolescence [38]. Third, the dataset is not comprehensive in its coverage of pregnancy information. Birth weight assessment relied on maternal recall rather than clinical report; however, the validity of maternal recall of birth weight has been verified [39]. Prenatal predictors of infant size that were not available in the dataset (e.g., gestational weight gain and gestational diabetes) precluded examination of whether preconception obesity operates independently of them. Finally, our interest in including repeated measures of preconception exposures to capture their timing and sequencing, in conjunction with the timing of the Wave IV interview, limited our sample to births occurring between the maternal ages of 18 and 32. Although the majority of births in the US occur annually to women in this age range [40], our findings may not be generalizable to births occurring at younger or older maternal ages. The 
generalizability of our findings to women of higher socioeconomic status also may be limited because higher educational attainment is correlated with delayed childbearing.

\title{
Conclusions
}

This study contributes to the ongoing discourse about the utility of applying a life course perspective to research on perinatal health [10]. In addition, it offers new evidence in support of recent calls for a focus on preconception health, which have been largely absent empirical support. While our evidence pertains solely to obesity, current trends in other health issues (e.g., cardiovascular disease) related to this indicator of preconception health status suggest that it is a worthwhile intervention target for more than one reason. Moreover, our study indicates that intervention may be most effective in reducing adverse birth outcomes if focused on maintenance of healthy weight and prevention of overweight in female adolescents. The absence of significant associations between the other preconception health indicators and birth weight does not mean that preconception care focused on these indicators is an unwarranted (and potentially ineffective) intervention strategy. At least with respect to the health behaviors included in this study, which are notoriously difficult to change, increasing the timeframe for interventions designed to address them beyond the approximately 9-month window within which prenatal care occurs would still be beneficial. It is reasonable to expect that it would be beneficial for addressing other behavioral factors as well, including abuse of illicit drugs. What we do not know is the extent to which this approach would be similarly beneficial for non-behavioral preconception factors, such as neighborhood deprivation, social service availability, and environmental hazards, that fall outside the purview of the health sector. Future research using prospective longitudinal datasets should explore this question in order to most effectively prevent the adverse health and developmental outcomes that can result from suboptimal birth weights.

\section{Acknowledgments}

This research was supported by the Eunice Kennedy Shriver National Institute of Child Health \& Human Development at the National Institutes of Health (grant numbers R01-HD057073, R01-HD058535, and T32HD052468). Related preliminary analyses were presented in June 2011 at the $3^{\text {rd }}$ National Summit on Preconception Health and Health Care, Tampa, FL, and at the annual meeting of the Society for Pediatric and Perinatal Epidemiologic Research, Montréal, QC.

This research uses data from Add Health, a program project directed by Kathleen Mullan Harris and designed by J. Richard Udry, Peter S. Bearman, and Kathleen Mullan Harris at the University of North Carolina at Chapel Hill, and funded by a grant P01-HD31921 from the Eunice Kennedy Shriver National Institute of Child Health and Human Development, with cooperative funding from 23 other federal agencies and foundations. Special acknowledgment is due Ronald R. Rindfuss and Barbara Entwisle for assistance in the original design. Information on how to obtain the Add Health data files is available on the Add Health website (http://www.cpc.unc.edu/ addhealth). No direct support was received from grant P01-HD31921 for this analysis.

The funding organization played no role in the design and conduct of the study, analysis and interpretation of data, or preparation, review or approval of the manuscript. The content is solely the responsibility of the authors and does not necessarily represent the official views of the Eunice Kennedy Shriver National Institute of Child Health \& Human Development or the National Institutes of Health. All authors contributed to the writing of the first draft of the manuscript, did not award payment to anyone to produce the manuscript, and have no conflicts of interest.

The authors would like to thank Chirayath Suchindran for assistance with statistical analysis. His work on this project was supported by the aforementioned grant R01-HD057073, and he has no conflicts of interest. The authors affirm that all significant contributors to this work have been acknowledged.

\section{ABBREVIATIONS}

\author{
Add Health The National Longitudinal Study of Adolescent Health \\ BMI body mass index
}




$\begin{array}{ll}\text { CDC } & \text { The Centers for Disease Control and Prevention } \\ \text { CI } & \text { confidence interval } \\ \text { GED } & \text { general educational development certificate } \\ \text { IRB } & \text { Institutional Review Board } \\ \text { LBW } & \text { low birth weight } \\ \text { OR } & \text { odds ratio } \\ \text { SE } & \text { standard error of the mean } \\ \text { SES } & \text { socioeconomic status } \\ \text { US } & \text { United States }\end{array}$

\section{References}

1. McCormick MC. The contribution of low birth weight to infant mortality and childhood morbidity. N Engl J Med. 1985; 312:82-90. [PubMed: 3880598]

2. Henriksen T. The macrosomic fetus: a challenge in current obstetrics. Acta Obstet Gynecol Scand. 2008; 87:134-145. [PubMed: 18231880]

3. Barker DJ. The developmental origins of adult disease. J Am Coll Nutr. 2004; 23(suppl):588s-595s. [PubMed: 15640511]

4. Kanaka-Gantenbein C. Fetal origins of adult diabetes. Ann N Y Acad Sci. 2010; 1205:99-105. [PubMed: 20840260]

5. Lu MC. We can do better: improving perinatal health in America. J Womens Health. 2010; 19(3): 569-574.

6. Haas JS, Fuentes-Afflick E, Stewart AL, et al. Prepregnancy health status and the risk of preterm delivery. Arch Pediatr Adolesc Med. 2005; 159(1):58-63. [PubMed: 15630059]

7. Misra DP, Guyer B, Allston A. Integrated perinatal health framework: a multiple determinants model with a life span approach. Am J Prev Med. 2003; 25(1):65-75. [PubMed: 12818312]

8. Johnson K, Posner SF, Biermann J, et al. Recommendations to improve preconception health and health care--United States: a report of the CDC/ATSDR preconception care work group and the select panel on preconception care. MMWR Recomm Rep. 2006; 55(RR-6):1-23. [PubMed: 16617292]

9. American Medical Association Women Physicians Congress. Policy compendium on issues relating to women in medicine and women's health. Chicago, IL: American Medical Association; 2007.

10. Richardson, LJ.; Hussey, JM.; Strutz, KL. A life course perspective on maternal and child health. In: Kotch, JB., editor. Maternal and Child Health: Programs, Problems, and Policy in Public Health. 3. Sudbury, MA: Jones and Bartlett Publishers; in press

11. Lu MC, Halfon N. Racial and ethnic disparities in birth outcomes: a life-course perspective. Matern Child Health J. 2003; 7(1):13-30. [PubMed: 12710797]

12. Harris K, Gordon-Larsen P, Chantala K, Udry J. Longitudinal trends in race/ethnic disparities in leading health indicators from adolescence to young adulthood. Arch Pediatr Adolesc Med. 2006; 160(1):74-81. [PubMed: 16389215]

13. US Department of Health and Human Services. Office of Disease Prevention and Health Promotion. Healthy People 2020. Washington, DC: Available at: http://www.healthypeople.gov

14. Korenbrot CC, Steinberg A, Bender C, Newberry S. Preconception care: a systematic review. Matern Child Health J. 2002; 6(2):75-88. [PubMed: 12092984]

15. Arendas K, Qiu Q, Gruslin A. Obesity in pregnancy: pre-conceptional to postpartum consequences. J Obstet Gynaecol Can. 2008; 30(6):477-488. [PubMed: 18611299]

16. Lof M, Hilakivi-Clarke L, Sandin S, Weiderpass E. Effects of pre-pregnancy physical activity and maternal BMI on gestational weight gain and birth weight. Acta Obstet Gynecol Scand. 2008; 87(5):524-530. [PubMed: 18446535] 
17. Whitehead N, Lipscomb L. Patterns of alcohol use before and during pregnancy and the risk of small-for-gestational-age birth. Am J Epidemiol. 2003; 158(7):654-662. [PubMed: 14507601]

18. Weisman CS, Misra DP, Hillemeier MM, et al. Preconception predictors of birth outcomes: Prospective findings from the Central Pennsylvania Women's Health Study. Matern Child Health J. 2011; 15:829-835. [PubMed: 19472041]

19. Harville EW, Boynton-Jarrett R, Power C, Hypponen E. Childhood hardship, maternal smoking, and birth outcomes: a prospective cohort study. Arch Pediatr Adolesc Med. 2010; 164(6):533-539. [PubMed: 20530303]

20. Richardson, LJ. The social structural context of pregnancy and adverse birth outcomes: The role of race, place, and time (doctoral dissertation). Chapel Hill, NC: University of North Carolina; 2009.

21. Gavin AR, Hill KG, Hawkins JD, Maas C. The role of maternal early-life and later-life risk factors on offspring low birth weight: findings from a three-generational study. J Adolesc Health. 2011; 49:166-171. [PubMed: 21783049]

22. Harris, KM.; Halpern, CT.; Whitsel, EA., et al. The National Longitudinal Study of Adolescent Health: research design. Chapel Hill, NC: Carolina Population Center, University of North Carolina; 2009. Available at: http://www.cpc.unc.edu/projects/addhealth/design

23. Kuczmarski RJ, Ogden CL, Guo SS, et al. 2000 CDC growth charts for the United States: methods and development. Vital Health Stat. 2002; (246):1-190.

24. World Health Organization. Obesity: preventing and managing the global epidemic: report of a WHO consultation. World Health Organ Tech Rep Ser. 2000; 894:1-253.

25. Office of Disease Prevention and Health Promotion. Physical activity guidelines for Americans. Washington, DC: US Department of Health and Human Services; 2008.

26. Gordon-Larsen P, Nelson MC, Popkin BM. Longitudinal physical activity and sedentary behavior trends: adolescence to adulthood. Am J Prev Med. 2004; 27(4):277-283. [PubMed: 15488356]

27. National Institute on Alcohol Abuse and Alcoholism. Helping patients with alcohol problems: a health practitioner's guide. Bethesda, MD: National Institutes of Health; 2004.

28. Feng Z, McLerran D, Grizzle J. A comparison of statistical methods for clustered data analysis with Gaussian error. Stat Med. 1996; 15(16):1793-1806. [PubMed: 8870161]

29. Baeten J, Bukusi E, Lambe M. Pregnancy complications and outcomes among overweight and obese nulliparous women. Am J Public Health. 2001; 91(3):436-440. [PubMed: 11236410]

30. Fleten C, Stigum H, Magnus P, Nystad W. Exercise during pregnancy, maternal prepregnancy body mass index, and birth weight. Obstet Gynecol. 2010; 115(2):331-337. [PubMed: 20093907]

31. Lee H, Lee D, Guo G, Harris KM. Trends in body mass index in adolescence and young adulthood in the United States: 1959-2002. J Adolesc Health. 2011; 49:601-608. [PubMed: 22098770]

32. Owe KM, Nystad W, Bo K. Association between regular exercise and excessive newborn birth weight. Obstet Gynecol. 2009; 114(4):770-776. [PubMed: 19888034]

33. Voldner N, Froslie KF, Bo K, et al. Modifiable determinants of fetal macrosomia: role of lifestylerelated factors. Acta Obstet Gynecol Scand. 2008; 87(4):423-429. [PubMed: 18382868]

34. Passaro K, Little R, Savitz D, Noss J. The effect of maternal drinking before conception and in early pregnancy on infant birthweight. Epidemiology. 1996; 7(4):377-383. [PubMed: 8793363]

35. Butler NR, Goldstein H, Ross EM. Cigarette smoking in pregnancy: its influence on birth weight and perinatal mortality. Br Med J. 1972; 2(5806):127-130. [PubMed: 5017304]

36. Kirchengast S, Hartmann B. Nicotine consumption before and during pregnancy affects not only newborn size but also birth modus. J Biosoc Sci. 2003; 35(2):175-188. [PubMed: 12664956]

37. Nordstrom ML, Cnattingius S. Smoking habits and birthweights in two successive births in Sweden. Early Hum Dev. 1994; 37(3):195-204. [PubMed: 7925078]

38. Goodman E, Hinden BR, Khandelwal S. Accuracy of teen and parental reports of obesity and body mass index. Pediatrics. 2000; 106:52-58. [PubMed: 10878149]

39. Adegboye ARA, Heitmann BL. Accuracy and correlates of maternal recall of birthweight and gestational age. BJOG. 2008; 115(7):886-893. [PubMed: 18485168]

40. Martin JA, Hamilton BE, Sutton PD, et al. Births: final data for 2007. Natl Vital Stat Rep. 2010; 58(24):1-85. [PubMed: 21254725] 
Table 1

Characteristics of the Study Population, National Longitudinal Study of Adolescent Health, 1994-2008

\begin{tabular}{|c|c|c|c|c|}
\hline \multirow[b]{2}{*}{ Characteristic } & \multicolumn{3}{|c|}{ Birth Weight } & \multirow[b]{2}{*}{ Total $(n=3436)$} \\
\hline & LBW (n = 269) & Normal $(n=2848)$ & Macrosomia $(n=319)$ & \\
\hline$\%$ of total & 8.3 & 82.2 & 9.5 & 100 \\
\hline \multicolumn{5}{|l|}{ Demographic Confounders } \\
\hline Age, mean (SE), y & $25.8(0.3)$ & $26.0(0.1)$ & $26.0(0.3)$ & $26.0(0.1)$ \\
\hline \multicolumn{5}{|l|}{ Parity, \% } \\
\hline Nulliparous & 58.4 & 51.6 & 51.8 & 52.2 \\
\hline Parous & 41.6 & 48.4 & 48.2 & 47.8 \\
\hline \multicolumn{5}{|l|}{ Race/Ethnicity, \% } \\
\hline Non-Hispanic White & 55.9 & 66.0 & 74.9 & 66.0 \\
\hline Non-Hispanic Black & 24.3 & 15.1 & 12.6 & 15.6 \\
\hline Latina & 11.5 & 11.7 & 8.0 & 11.3 \\
\hline Asian/Pacific Islander & 2.5 & 2.7 & 0.9 & 2.5 \\
\hline Other & 4.8 & 4.1 & 2.8 & 4.0 \\
\hline \multicolumn{5}{|l|}{ Nativity, \% } \\
\hline Foreign-born to foreign-born parent & 2.9 & 4.5 & 2.8 & 4.2 \\
\hline Native-born to foreign-born parent & 11.3 & 8.9 & 3.5 & 8.6 \\
\hline Native-born to native-born parent & 85.2 & 86.5 & 93.1 & 87.0 \\
\hline \multicolumn{5}{|l|}{ Childhood SES } \\
\hline \multicolumn{5}{|l|}{ Mother's Educational Attainment, $\%$} \\
\hline Less than high school & 16.9 & 19.6 & 9.9 & 18.4 \\
\hline GED & 5.4 & 4.9 & 5.2 & 5.0 \\
\hline High school diploma & 34.9 & 29.3 & 37.0 & 30.5 \\
\hline Some college or trade school & 25.7 & 26.3 & 25.3 & 26.2 \\
\hline Completed college or more & 13.4 & 16.0 & 18.3 & 16.0 \\
\hline Any Household Receipt of Public Assistance, \% & 17.4 & 19.6 & 11.9 & 18.6 \\
\hline \multicolumn{5}{|l|}{ Preconception Health Status Indicators } \\
\hline \multicolumn{5}{|l|}{ Cigarette Smoking, $\%$} \\
\hline Neither time point & 53.4 & 52.7 & 54.9 & 53.0 \\
\hline Adolescence only & 10.0 & 10.5 & 8.2 & 10.2 \\
\hline Adulthood only & 16.8 & 15.5 & 17.0 & 15.7 \\
\hline Both time points & 18.8 & 19.2 & 20.0 & 19.3 \\
\hline \multicolumn{5}{|l|}{ Overweight/Obesity, $\%$} \\
\hline Neither time point & 43.7 & 47.9 & 38.5 & 46.6 \\
\hline Adolescence only & 2.9 & 1.0 & 0.2 & 1.1 \\
\hline Adulthood only & 23.7 & 27.9 & 36.9 & 28.4 \\
\hline Both time points & 19.1 & 15.4 & 16.3 & 15.8 \\
\hline \multicolumn{5}{|l|}{ Adequate Physical Activity, $\%$} \\
\hline Neither time point & 33.8 & 28.0 & 27.2 & 28.4 \\
\hline Adolescence only & 30.4 & 32.7 & 27.0 & 32.0 \\
\hline
\end{tabular}




\begin{tabular}{|c|c|c|c|c|}
\hline \multirow[b]{2}{*}{ Characteristic } & \multicolumn{3}{|c|}{ Birth Weight } & \multirow[b]{2}{*}{ Total $(n=3436)$} \\
\hline & LBW $(n=269)$ & Normal $(n=2848)$ & Macrosomia $(n=319)$ & \\
\hline Adulthood only & 12.1 & 13.2 & 15.7 & 13.4 \\
\hline Both time points & 23.1 & 25.9 & 30.2 & 26.1 \\
\hline \multicolumn{5}{|l|}{ Heavy Drinking, $\%$} \\
\hline Neither time point & 57.6 & 55.8 & 54.4 & 55.8 \\
\hline Adolescence only & 11.1 & 13.9 & 13.2 & 13.6 \\
\hline Adulthood only & 19.4 & 20.2 & 21.2 & 20.2 \\
\hline Both time points & 11.3 & 9.1 & 10.1 & 9.3 \\
\hline \multicolumn{5}{|l|}{ Fair/Poor Health, \% } \\
\hline Neither time point & 83.7 & 87.3 & 88.6 & 87.2 \\
\hline Adolescence only & 7.1 & 6.1 & 7.5 & 6.3 \\
\hline Adulthood only & 7.0 & 4.8 & 2.6 & 4.8 \\
\hline Both time points & 1.5 & 1.7 & 1.3 & 1.7 \\
\hline \multicolumn{5}{|c|}{ Prenatal Health Status Indicators } \\
\hline Any Smoking, $\%$ & 24.4 & 21.1 & 14.1 & 20.7 \\
\hline Any Drinking, $\%$ & 3.1 & 6.3 & 5.5 & 5.9 \\
\hline \multicolumn{5}{|c|}{ Entry into Prenatal Care, \% } \\
\hline First trimester & 88.8 & 91.1 & 91.2 & 90.9 \\
\hline Second trimester & 4.5 & 3.8 & 2.8 & 3.7 \\
\hline Third trimester & 1.9 & 2.0 & 3.9 & 2.1 \\
\hline No care & 4.0 & 1.5 & 0.6 & 1.6 \\
\hline
\end{tabular}

Abbreviations: GED, general educational development certificate; LBW, low birth weight; \%, weighted percent; SE, standard error of the mean; SES, socioeconomic status. 


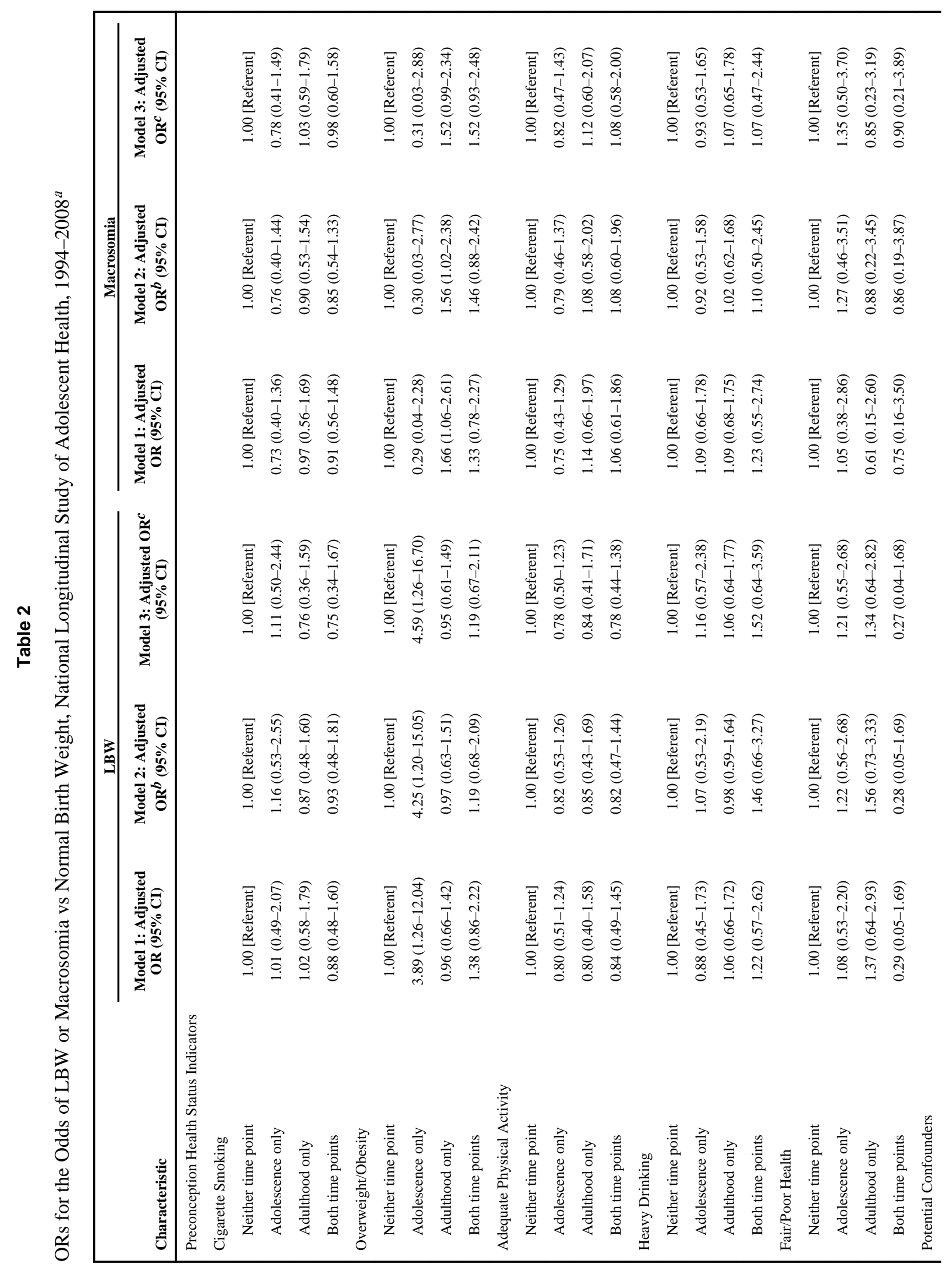




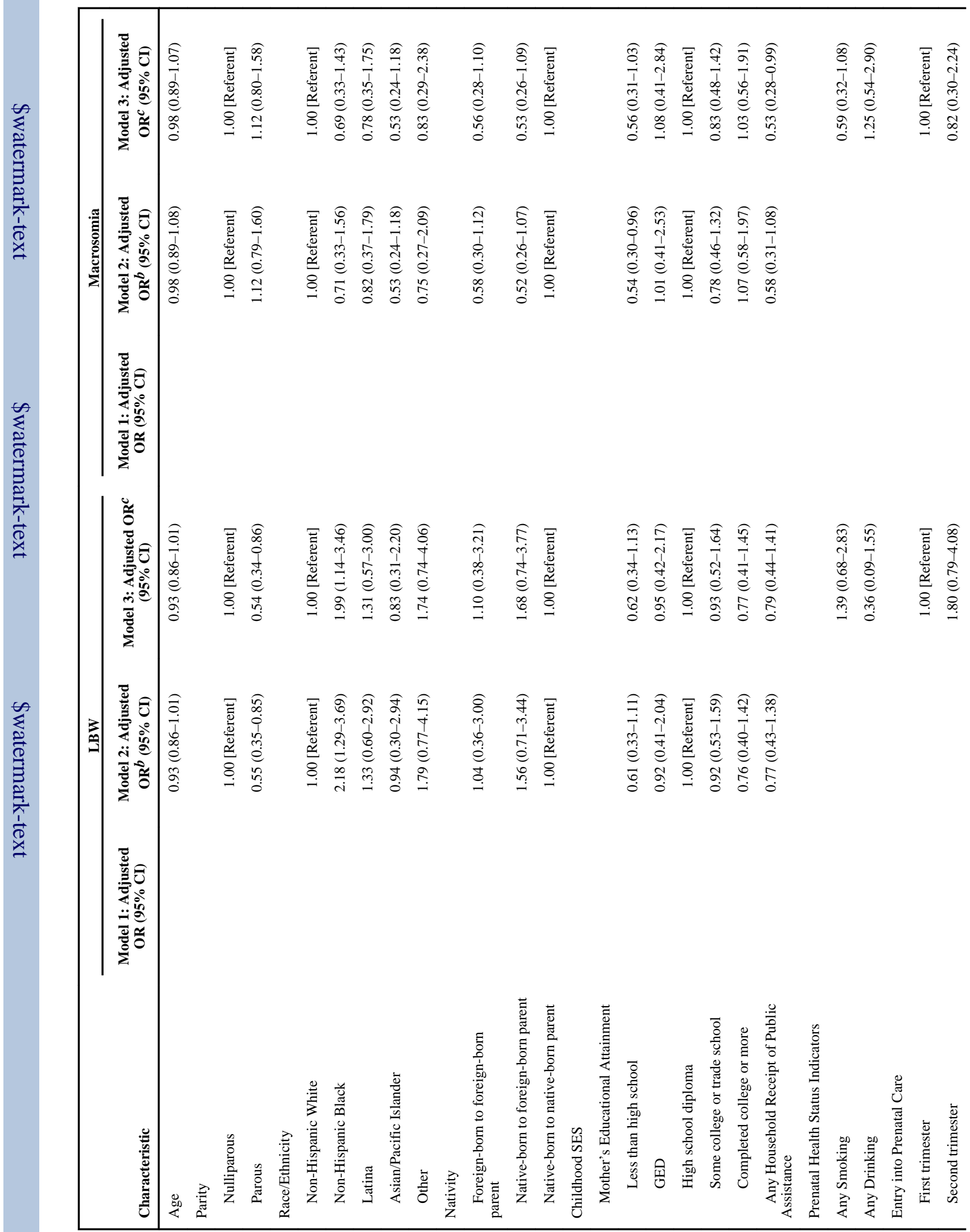




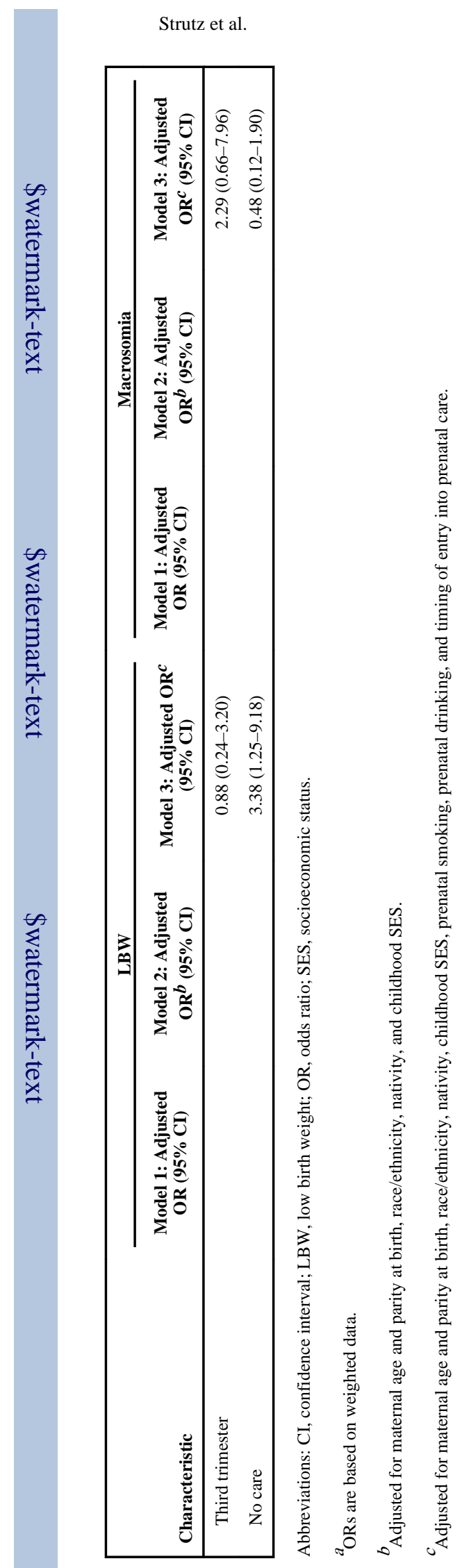

Page 14

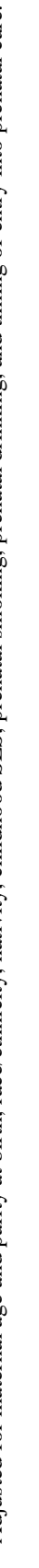




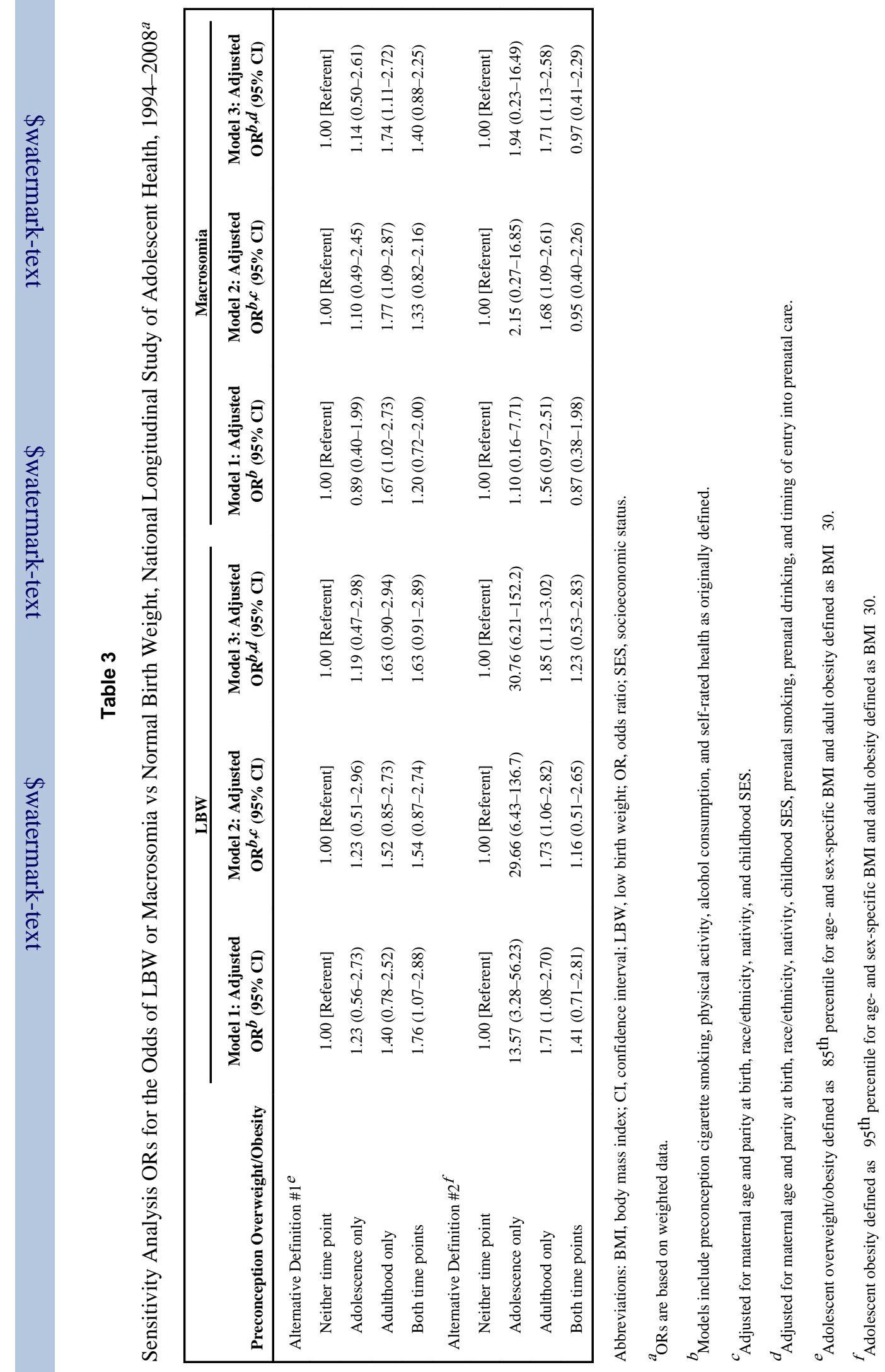

